\title{
EDUCACIÓN POPULAR Y PARADIGMAS EMANCIPADORES
}

\section{Resumen}

El artículo sintetiza el estudio documental realizado por el autor a solicitud del Consejo de Educación de Adultos de América Latina (CEAAL), acerca de la contribución de la Educación Popular (EP) en la construcción de paradigmas alternativos. Luego de un balance de la reciente producción bibliográfica sobre el tema, el autor propone las fuentes desde las cuales se puede contribuir desde la EP a la reconstrucción del pensamiento crítico emancipador desde América Latina. Además, plantea y desarrolla los rasgos de dicho pensamiento contra-hegemónico, y sus desafíos para las pedagogías críticas, en el actual momento histórico del continente.

Palabras claves: Educación popular, paradigma, pedagogías críticas, pensamiento crítico.

\section{EDUCAÇÃO POPULAR Y PARADIGMAS EMANCIPADORES}

\section{Resumo}

O artigo resume o estudo documental feito pelo autor ao pedido do Conselho de Educação de Adultos de América Latina (CEAAL), sobre a contribuição da instrução popular na construção de paradigmas alternativos. Após um contrapeso da produção bibliográfica recente na matéria, o autor propõe as fontes pelas quais é possível contribuir á EP e á reconstrução do pensamento crítico emancipatório em Latinoamérica. Além, levanta e desenvolve às características deste pensamento e seus desafios para a Educação Popular, no momento histórico atual do continente.

Palavras chaves: Educação popular, paradigma, pedagogia crítica, pensamento crítico.

\section{POPULAR EDUCATION AND EMANCIPATED PARADIGMS}

\section{Abstract}

This article synthesizes the documentary study made by the author to request of the Council of Education of Adults of Latin America (CEAAL), about the contribution of the popular education in the construction of alternative paradigms. After a balance of the recent bibliographical production on this matter, the author proposes the sources from which it is possible to contribute from the PE to the reconstruction of the emancipator critical thought from Latin America. In addition, it comes up and develops the characteristics of this contra-hegemonic thought and its challenges for critical pedagogies, at the present historical moment of the continent.

Key words: Popular education, paradigm, critical pedagogy, critical thought.

* Doctor en Estudios Latinoamericanos de la Universidad Nacional Autónoma de México. Profesor e investigador del Departamento de Ciencias Sociales y del Doctorado en Educación de la Universidad Pedagógica Nacional de Colombia.

Correo electrónico: atorres@pedagogica.edu.co

Artículo recibido el 12 de marzo de 2009 y aprobado el 22 de mayo de 2009 


\section{PRESENTACIÓN}

En sus cuatro décadas de existencia en América Latina, la Educación Popular (en adelante, EP) se ha convertido en un movimiento educativo y una corriente pedagógica crítica que representa el principal aporte del continente al debate pedagógico contemporáneo (Torres, 2008). En esta configuración como campo intelectual han contribuido autores como Paulo Freire, João Francisco de Souza y Carlos Núñez, así como los centros de apoyo y redes de organizaciones civiles que desarrollan o acompañan prácticas educativas populares.

El Consejo de Educación de Adultos de América Latina (CEAAL) ha sido desde la década de 1980 el principal espacio de debate y construcción discursiva de la EP, a través de la Revista La Piragua, sus redes temáticas y sus encuentros regionales. En su VI Asamblea realizada en Recife (Brasil) en 2004, definió los ejes estratégicos en torno a los cuales organizar su acción entre 2005 y 2008. El primero de ellos se denominó "Contribución del CEAAL y de la EP para la construcción de paradigmas de emancipación" y sintetiza una preocupación del CEAAL, en torno a redefinir los supuestos políticos y epistemológicos del discurso de la Educación Popular de cara a las transformaciones del panorama político y cultural latinoamericano y mundial actual:

En su casi medio siglo de existencia, a raíz de los grandes cambios políticos de fines de los 80, la EP se cuestiona acerca de las concepciones de transformación social y acción política que la han inspirado. En este contexto, cabe preguntarse ¿qué continúa vigente, qué ha cambiado y qué necesita repensarse dentro de la EP? (Puntual, 2005, p. 7)

Transcurridos cuatro años, el Comité Ejecutivo de CEAAL consideró pertinente hacer un balance de los avances en torno a esta problemática. Dicho interés se concretó en el proyecto de investigación "Educación popular y nuevos paradigmas a partir de la producción del CEAAL 2004-2008", bajo mi responsabilidad. Para facilitar tal empresa, la
Secretaria General solicitó a los centros miembros el envío de los documentos producidos desde los encuentros regionales y demás eventos del CEAAL, los cuales se convirtieron en el corpus del estudio.

Con base en los resultados del análisis documental, este artículo rescata y hace visibles los aportes presentes en los textos recibidos, a la vez que comparte mis reflexiones como educador e incorpora algunos planteamientos provenientes de pensadores críticos alrededor de los sentidos, contenidos e implicaciones educativas de los paradigmas emancipadores.

El texto se articula en torno a algunas preguntas que me fui haciendo a lo largo de la lectura crítica del "corpus documental" y de mi propio posicionamiento frente al desafío que representa repensar la EP en el contexto más amplio de los procesos históricos latinoamericanos: ¿por qué la búsqueda de "nuevos paradigmas" desde la EP?, ¿cómo se están entendiendo los paradigmas emancipadores?, ¿desde dónde contribuir a la construcción de un pensamiento alternativo?, ¿por dónde comenzar?, ¿cuáles pueden ser las ideas centrales y las rutas críticas de esa construcción?

\section{LAS RAZONES DE UNA BÚSQUEDA}

La preocupación desde la educación popular, en particular del CEAAL, frente a los "nuevos paradigmas", es tanto intelectual como política, pues está asociada a su posicionamiento crítico y a su opción liberadora. En efecto, como lo plantea Esther Pérez (2000), la naturaleza de la EP no es disciplinar sino política: forma parte y alimenta una tradición latinoamericana de resistencia y construcción de alternativas a las estructuras y estrategias de dominación impuestas desde hace más de 5 siglos.

En particular, la EP, al igual que la Teología de la Liberación, la comunicación alternativa, la Investigación Acción Participativa y la Filosofía de la Liberación,

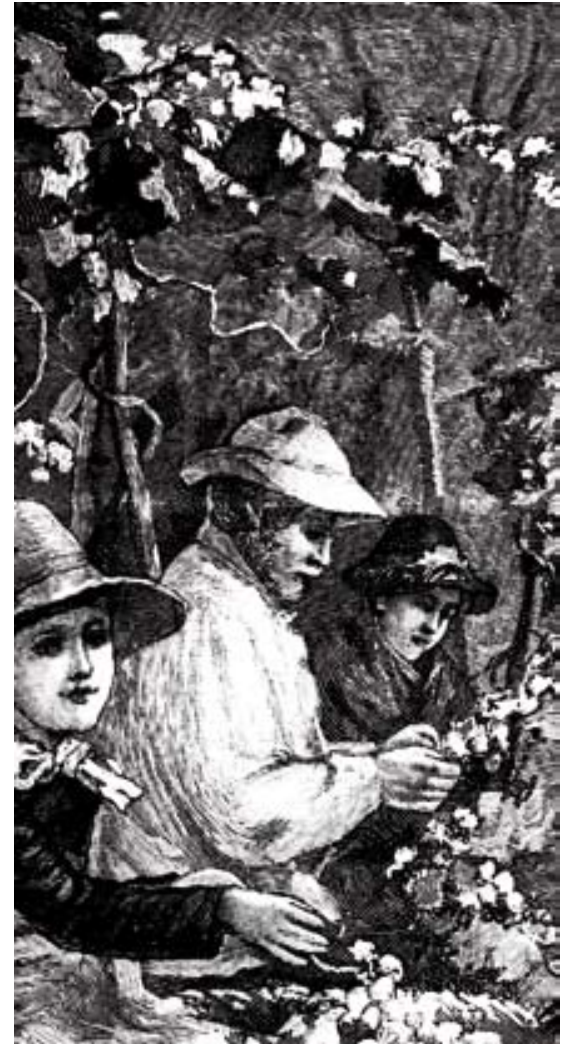

constituye una corriente de pensamiento y un conjunto de prácticas sociales intencionalmente dirigidas a la transformación de las estructuras injustas y orientadas desde visiones de futuro alternativas a los modelos hegemónicos. En fin, la EP representa una opción ética y política que no se reduce a sus interpretaciones de la realidad social; más bien, éstas se subordinan a unas apuestas emancipadoras conformadas desde diferentes fuentes como las memorias y los imaginarios colectivos, sistemas de creencias y representaciones, voluntades y utopías.

Es por ello que desde los documentos producidos desde el CEAAL, la necesidad de nuevos paradigmas se remita al desafío impuesto por las transformaciones en el panorama político mundial y latinoamericano; en particular, los referentes a las experiencias históricas del llamado socialismo soviético, a las fuerzas políticas de izquierda, a los movimientos populares y culturales alternativos, a la hegemonía casi total del neoliberalismo en la región y, más 
recientemente, a la emergencia de gobiernos democráticos y progresistas en algunos países.

Por otra parte, el reclamo por los "nuevos paradigmas" se argumenta desde el reconocimiento del agotamiento o crisis de las "coordenadas teóricas" críticas que orientaron el pensamiento y la acción de la izquierda social y política mundial y latinoamericana, en particular el marxismo en su versión ortodoxa. Es frecuente la alusión a la insuficiencia o impertinencia de estas claves de lectura para dar cuenta de las recientes transformaciones sociales, políticas y culturales. Se habla de ampliar y renovar los referentes interpretativos que alimentaron los discursos y las prácticas fundacionales de la EP. En términos de la compañera Isabel Vinent (2004, p 7):

La educación popular podría estar superando uno de los dilemas teóricos más críticos: su vigencia como planteamiento emancipador ante los paradigmas y contextos actuales. Los contemporáneos cambios paradigmáticos en el campo del conocimiento científico, los cambios contextuales imperantes en el terreno de la política y la economía y los nuevos sujetos emergentes en las luchas populares marcan un punto de no retorno en la historia de la educación popular.

Así, la otra cara de la crítica a estos marcos conceptuales, es la necesidad de incorporar y construir nuevas alternativas de comprensión de las realidades emergentes. Más aún cuando se reconoce que el neoliberalismo se ha convertido en el "paradigma dominante", capaz incluso de incorporar y cooptar algunas categorías críticas en función del proyecto hegemónico. Por ello, "los paradigmas emancipadores", son entendidos como el conjunto de planteamientos políticos, teóricos y éticos alternativos al "pensamiento y modelo único".

\section{¿CÓMO ENTENDER LOS PARADIGMAS EMANCIPADORES?}

Si bien es cierto que hay un consenso en torno a la necesidad política de los "nue- vos paradigmas", no lo hay en cuanto a la manera de entender el carácter y los alcances del concepto. Ya en un estudio anterior (Torres, 2008), se señalaban diferentes sentidos del término, que oscilaban entre los que ven en los paradigmas a los grandes marcos culturales ("vivimos crisis de época"), pasando por los que los ven como sistemas de ideas o de conceptos que orientan la práctica ("se necesita lanzar conceptos que generen nuevos sitios de significación"), hasta quienes los entienden en una clave político ideológica ("hablamos del paradigma del socialismo").

Durante el actual periodo de análisis, se acota el sentido del concepto. Leis (2007) define los paradigmas como "un conjunto de conocimientos y creencias que forman una visión del mundo (cosmovisión), articulados a una concepción de la realidad en determinado periodo histórico" (p. 3). Dicha posición coincide con los planteamientos de los especialistas que lo conciben como una concepción del mundo compartida por una población:

Participando en las matrices sociales (que incluyen la ciencia y las culturas de las que formamos parte) adquirimos formas de comprender y participar, metáforas y parámetros, ejes cognitivos y destrezas especificas. La subjetividad y las relaciones sociales se organizan en el trazado de esas metáforas, de esos horizontes que generan presuposiciones y expectativas, configurando creencias, epistemologías cotidianas y visiones de futuro (Fried, 1994, p. 16).

\section{En palabras de Edgar Morin (1991):}

Un paradigma contiene, para cualquier discurso que se efectúe bajo su imperio, los conceptos fundamentales o categorías rectoras de inteligibilidad, al mismo tiempo que el tipo de relaciones lógicas de atracción/repulsión (conjunción, disyunción, implicación u otras) entre estos conceptos o categorías (p. 261).

En el mismo texto, Leis señala que los paradigmas son emancipadores, si

dan cabida a las visiones y propuestas que muestran su desavenencia con las desigualdades y asimetrías del orden imperante, por lo que prefiguran una sociedad justa y humanizada [...] Se traducen en conceptos operativos, susceptibles de enriquecerse desde las diversas prácticas y corrientes contestarias de pensamiento que se oponen al sistema de dominación múltiple y sus causas (Leis, 2007, p. 5).

De este modo, cuando desde la EP se habla de paradigmas emancipadores, simultáneamente estamos haciendo mención a una dimensión gnoseológica (interpretaciones de la realidad), a una dimensión política y ética (posicionamiento frente a dicha realidad) y a una dimensión práctica: dicha concepciónopción orienta las acciones individuales y colectivas. Desde la ya clásica consigna "ver-juzgar-actuar" hasta las elaboraciones actuales, la preocupación de la educación popular por el conocimiento ha estado y está en función de las prácticas transformadoras de realidad, es una pedagogía de la praxis.

En efecto, en la medida en que afirmamos que la EP no es una disciplina, ni sólo un campo intelectual, sino una acción cultural y pedagógica comprometida, la preocupación no es exclusivamente epistemológica o teórica, sino eminentemente política y práctica. Ya en 2003, el mismo Leis planteaba que el paradigma es "una especie de marco para la acción, en un punto de referencia para la acción". De forma más contundente, Pedro Puntual lo afirmó en el encuentro de CEAAL México realizado en Chapala, Jalisco, en 2006: "para nosotros conocer sólo tiene sentido si es para ejercer una mejor acción transformadora".

A la vez que se acota su significado, este modo de asumir la idea de paradigma desde la EP introduce nuevos desafíos de carácter gnoseológico, político y pedagógico. En el plano cognitivo, ya no solo plantea la exigencia de elaborar ideas y conceptos "que generen nuevos sitios de significación que se conviertan en referencias políticas y educativas para las prácticas sociales alternativas realizadas por diferentes actores" (Pagano, 2000, p. 35); también implica afectar las subjetividades que enmarcan y orientan las prácticas e interacciones de educadores y educandos, que ade- 
más de razón y conocimiento, involucran convicciones, representaciones, imaginarios culturales, valores, actitudes y esperanzas.

Así mismo, lo político no se reduce a la definición de claras opciones ideológicas y programas para orientar la acción política y educativa, sino también voluntades, opciones, compromisos, apuestas valorativas y utopías con la capacidad de construir una nueva hegemonía ética y cultural. En consecuencia, el campo de acción pedagógica de la EP en la formación, desde paradigmas emancipadores, no se limita al plano de la conciencia, se ensancha al plano de la subjetividad, que en su dimensión individual y colectiva gobierna las lecturas de realidad, los procesos de construcción de identidad, los vínculos y las opciones y voluntades de acción (Torres, 2007).

Esta preocupación por "aportar en la construcción de nuevos paradigmas emancipadores" no parte de cero. La EP como corriente pedagógica crítica, no sólo ha construido a lo largo de su trayectoria histórica un sistema de ideas y valores críticos compartidos, sino también un conjunto de creencias, saberes, representaciones, imaginarios y referentes simbólicos comunes. Hace más de una década Mario Osorio Márquez (1996, p 35), se refirió a la EP como el "paradigma dialógico" en contraste con los paradigmas de la esencia (clásico) y de la conciencia (moderno). Desde estos marcos interpretativos compartidos como paradigma subyacente, los individuos, los colectivos y las organizaciones de educación popular, orientan sus prácticas y establecen relaciones, a la vez que elaboran su sentido de pertenencia. Como "comunidad de sentido" (Berger y Lukmann, 1997), el movimiento de educación popular es, en sí mismo, una matriz de pensamiento y una subjetividad crítica.

Por otra parte, la EP forma parte de una tradición, de una corriente más amplia de pensamiento y acción alternativa, de profundo raigambre latinoamericano que se inicia en la década de los 60 del siglo pasado y llega hasta el presente, y de la cual forman parte otras corrientes y prác-

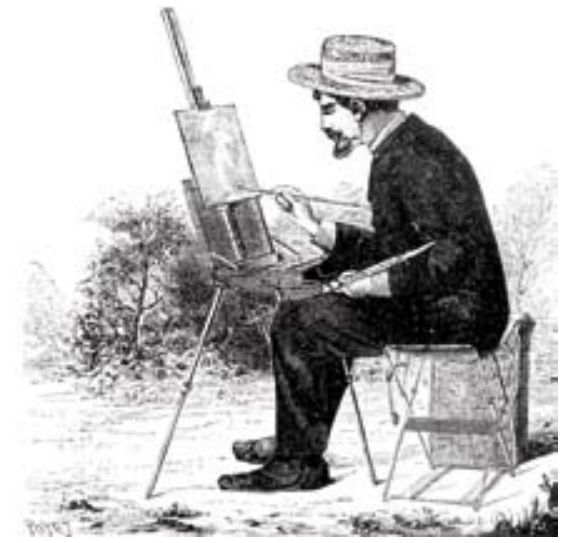

ticas como la Teología y la Filosofía de la Liberación, la Comunicación Alternativa y la Investigación Acción Participativa. Desde su especificidad pedagógica, la educación popular es "heredera de una vieja tradición: la de transformar el conjunto social, privilegiando la educación como herramienta fundamental" (Pérez 2000 , p. 43). Esta corriente crítica, estrechamente vinculada a los movimientos sociales latinoamericanos, tiene como rasgo central su propósito de contribuir en la construcción de unas sociedades más justas desde una opción promovida por los sectores populares, a partir de una crítica radical (ética y política) al orden social vigente. En palabras de Cesar Picón:

La identidad de la EP es su compromiso con los sectores populares, con sus movimientos sociales y sus organizaciones en una perspectiva emancipadora [...] El desafío que tiene la EP es ser consecuente y coherente con su identidad, y a partir de ello, abrirse a demandas sociales ampliadas y ante nuevos sujetos educativos populares, pero rechazando las concepciones y valoraciones del liberalismo (Picón, 2005, p 55).

Para efectos de este artículo, lo anterior significa que buena parte de sus interpretaciones, referentes discursivos, convicciones y visiones de futuro tienen su origen en esta tradición; así mismo, la EP ha irrigado el conjunto de movimientos y prácticas emancipadoras con sus ideas y propuestas: Freire no es patrimonio exclusivo de las pedagogías alternativas, sino del pensamiento emancipador mundial, pues como lo señala Jurjo Torres (2001) "es uno de los pedagogos más influyentes del siglo $\mathrm{XX}$, admirado y seguido por las personas progresistas, e incluso respetado por quienes mantienen concepciones ideológicas más conservadoras" (2001, p. 11).

\section{CONTRIBUCIÓN DE LA EDUCACIÓN POPULAR A LA FORMACIÓN DE NUEVOS PARADIGMAS CRÍTICOS}

Con lo dicho hasta ahora es evidente que la "construcción de nuevos paradigmas" no es tarea exclusiva de la EP y debe nutrirse de diferentes fuentes: por un lado, su propio acumulado como corriente educativa alternativa; por otro, otras corrientes culturales y prácticas desde las cuales se apunta hacia horizontes comunes; además, la elaboración colectiva de pensamiento, conocimiento y visiones de futuro emancipadoras, así como el reconocimiento y recuperación crítica de las subjetividades emergentes que se generan desde sus propias prácticas y otros movimientos alternativos. Veamos:

\section{El acumulado de pensamiento pedagógico crítico}

Hemos señalado cómo la educación popular constituye en sí misma una fuente de ideas pedagógicas emancipadoras de las cuales otras corrientes críticas se han nutrido. Sin lugar a dudas, la obra de Paulo Freire ocupa un lugar central y un referente imprescindible a la hora de re-construir pensamiento emancipador. En la última década algunos pedagogos latinoamericanos (João Francisco de Sousa, Carlos Nuñez, Alfredo Ghiso, Oscar Jara, Lola Cendales, Pedro Pontual, Moacir Gadotti) y de otras latitudes (Mc Claren, Giroux, Carlos Alberto Torres, Walsh), han retomado y recreado algunas de las ideas de Freire en torno a temáticas como la interculturalidad, la ética pedagógica, el diálogo, el compromiso, la formación de educadores y las pedagogías críticas. En el último periodo, colectivos CEAAL de diferentes países y regiones realizaron un gran 
número de eventos y seminarios, así como publicaciones sobre el maestro brasileño. También en universidades de varios países se ha creado la Cátedra Paulo Freire como espacio de discusión de su legado.

A la vez, desde la educación popular se han hecho aportes acerca de la cuestión metodológica y pedagógica de las prácticas sociales alternativas y la formación de educadores; propuestas como el diálogo de saberes y el diálogo cultural han sido incorporadas a otros discursos y prácticas educativas como la interculturalidad y el tratamiento de conflictos. La corriente de EP tiene fortalezas en algunas temáticas: la sistematización de experiencias, la incidencia en políticas públicas, la democracia participativa local y la alfabetización, como lo evidencia el contenido de los últimos números de La Piragua. En campos como la sistematización, los principales expertos latinoamericanos pertenecen a los centros afiliados al CEAAL (Cfr. La Piragua, núm. 23, 2006).

Dos temáticas en torno a las cuales las redes del CEAAL se han configurado como campos teórico-prácticos son la incidencia desde la EP en las políticas educativas y el papel de la EP en la construcción de democracia participativa y poder local. Con liderazgos claros de educadores como Nélida Céspedes y Pedro Puntual, pero con exponentes en casi todos los países, han sido varios los espacios de debate y construcción de pensamiento propio y alternativo; máxime cuando son temas que desde el discurso hegemónico también se reivindican

La alfabetización, temática que había jugado un papel central en la década de los años ochentas, y prácticamente abandonada en la siguiente, ha vuelto a cobrar relevancia por las iniciativas de organismos multilaterales y conferencias mundiales (Confintea, Plan Iberoamericano de Alfabetización, OEI, CAB) y las experiencias masivas emprendidas por gobiernos progresistas de la región como Venezuela, Bolivia y Ecuador. La educación popular -y el CEAAL-que cuenta con una amplia trayectoria y un acumulado propio en lo metodológico, tiene una oportunidad valiosa de incidir en su reconceptualización, en la definición de políticas y en orientación de acciones con poblaciones específicas.

El género -como perspectiva y como temática- hace presencia en diferentes discusiones y procesos del CEAAL. Como perspectiva, ha contribuido a enriquecer -muchas veces cuestionando algunos de sus discursos y prácticas - la corriente educativa popular; como temática, se plantea como ineludible en algunas de las prácticas educativas populares. En particular, para este periodo reciente, se compartió en el Foro del CEAAL Panamá de 2004, un documento de Isabel Vinent, donde plantea una discusión sobre la necesidad de conjugar tradición crítica y posmodernismo en la construcción de paradigmas emancipatorios desde la Educación Popular.

Un tema con presencia permanente en las discusiones de los colectivos CEAAL y en muchos números de La Piragua es el de los vínculos entre la Educación Popular y los Movimientos Sociales; Ios aportes se han centrado en destacar su relevancia actual, así como su caracterización y dimensión política, dándole un peso menor de los aspectos propiamente pedagógicos de este campo de acción educativa. En el número 27 de la revista La Piragua (2008) que estuvo dedicada al tema, aparecen valiosos aportes de María Rosa Goldar, Mario Garcés y Nadia Rodríguez.

Otra temática emergente cuyo posicionamiento proviene de otros campos pedagógicos, como la educación indígena, es el de la interculturalidad. João Francisco de Sousa (2001 y 2004) hizo formidables planteamientos desde los aportes de Freire. Por otra parte, en La Piragua N. ${ }^{\circ} 24$, las compañeras Marcela Tovar de México y Liliam Hidalgo del Perú pusieron en debate los presupuestos conceptuales e implicaciones prácticas de la educación intercultural. Sin embargo, falta mayor conocimiento de esta perspectiva crítica para entender las diferencias y conflictos culturales.
Algunas de estas contribuciones se han hecho desde los centros afiliados y en los espacios colectivos del CEAAL, pero también desde otros colectivos de educadores populares y de pedagogos pertenecientes a otras corrientes. Para ello es necesaria, la realización de los balances de esas discusiones y aportes recientes, así como la creación de espacios de discusión sobre las mismas con otros grupos y organizaciones de educadores que aún no pertenecen al Consejo; un buen ejemplo de ello fue el 4. ${ }^{\circ}$ Encuentro nacional de promotoras de desarrollo local y educadores populares, llevado a cabo por los compañeros de CEAAL México en noviembre de 2006.

Sin embargo, temáticas y prácticas educativas, en las que la educación popular posee un acumulado (por ejemplo, educación en derechos humanos) y en otros emergentes, tales como salud y seguridad alimentaria, trabajo con jóvenes e inmigrantes, justicia comunitaria y derecho alternativo, fueron escasamente documentados en las publicaciones del CEAAL.

\section{La sistematización de prácticas y saberes generados desde las mismas}

No sólo el CEAAL posee un saber valioso en torno a la sistematización de experiencias como modalidad investigativa; también buena parte de sus centros afiliados han sistematizado algunas de sus prácticas, proyectos y programas más significativos. Dichos ejercicios investigativos se han hecho cada vez más sistemáticos y sus alcances superan la simple reconstrucción descriptiva, profundizando en el análisis e interpretación de las problemáticas a las cuales se refieren.

Sin embargo, considero que todavía falta por reconocer, interpretar y potenciar buena parte de los saberes y subjetividades producidas desde las prácticas educativas populares -históricas y emergentes - de los Centros y redes del CEAAL, más allá de los contenidos mismos sobre los que trabajan. Tal vez una riqueza no reconocida es la referida a los saberes prácticos generados desde las experiencias singulares de 
las educadoras y los educadores, cuya sistematización aportaría a la aplazada reflexión sobre lo metodológico y lo pedagógico.

Finalmente, es necesario explorar, reconocer y potenciar los saberes y realidades emergentes con potencial emancipador que puedan contribuir en la generación y fortalecimiento de los paradigmas liberadores que exige el presente contexto. ¿Cuáles formas de relación, de acción y de pensamiento están generándose desde la multiplicidad de prácticas educativas populares?

\section{Ideas, valores y subjetividades emergentes desde las luchas y movimientos populares}

Otra fuente a la que hay que acudir en la construcción de referentes paradigmáticos alternativos es la de los saberes y valores que se están generando en el seno de las prácticas de resistencia $\mathrm{y}$ en las actuales acciones colectivas frente al modelo económico neoliberal, los regímenes políticos autoritarios y las múltiples formas de exclusión y subordinación características en los países de la región. Un rasgo histórico de la educación popular es su estrecha relación y vocación de apoyo a los movimientos y organizaciones populares. En buena medida, el discurso fundacional tuvo como referente movimientos protagonizados por actores sociales como los trabajadores, los campesinos y los pobladores urbanos; el discurso de la refundamentación, estuvo asociado a la emergencia de los nuevos movimientos sociales en torno a los derechos humanos, las reivindicaciones de las mujeres y los jóvenes, así como a la defensa de identidades culturales.

Desde mediados de la última década del siglo pasado, América Latina asiste a una verdadera reactivación de luchas sociales, entre las que sobresalen el movimiento indígena zapatista, los levantamientos indígenas en Bolivia y Ecuador, el Movimiento de los Sin Tierra en Brasil y las Asambleas Barriales y los Piqueteros en Argentina. Estos constituyen un desafío para la EP, tanto como sujetos educativos, como por su contri- bución a la construcción de paradigmas emancipatorios.

Por ejemplo, el movimiento neozapatista ha mostrado una gran imaginación política al introducir principios como los de "Mandar obedeciendo", "construir un mundo donde quepan muchos mundos" y "para todos todo, para nosotros nada" que reflejan nuevas concepciones y prácticas del ejercicio del poder y la emergencia de valores aglutinadores como la dignidad y la autonomía. Los movimientos indígenas han puesto en evidencia que la memoria, la solidaridad, los vínculos comunitarios y el territorio continúan siendo cimientos y contenidos de la acción colectiva y de la construcción de alternativas.

Especialistas en movimientos sociales también han mostrado cómo, desde los movimientos sociales, se están redefiniendo categorías políticas referentes a lo público, los derechos, la democracia (Dagnino, (2001) y la ciudadanía (De Souza 2006). Más aún, desde los movimientos sociales se están generando nuevas culturas políticas y políticas culturales emancipatorias que subvierten las significaciones dominantes de la política (Álvarez, Escobar y Dagnino, 2001). Por otro lado, Zibechi (2003) señala que un rasgo de estos movimientos sociales es su capacidad para formar sus propios intelectuales y un pensamiento propio.

Por último, resulta sugerente el ejercicio que lleva a cabo el maestro Orlando Fals Borda (2006) al reconocer que las luchas de los pueblos originarios de América Latina son portadoras de lo que denomina "valores sociales fundantes". Así, los pueblos indígenas han sido el reservorio de valores comunitarios como la solidaridad y la reciprocidad; los pueblos negros, el ideal de libertad; los campesinos y artesanos, la dignidad; finalmente, los colonos, la autonomía. Más allá de que se esté de acuerdo con la tipología, lo importante es constatar que la construcción de paradigmas emancipadores desde los movimientos populares reivindica no solo ideas sino valores, voluntades y actitudes sociales.
La tradición de pensamiento social crítico y otras prácticas intelectuales alternativas

Históricamente, la fuente teórica que alimentó los movimientos y discursos alternativos a lo largo del siglo XX fue el marxismo, en sus diferentes vertientes como el leninismo, el maoísmo y la obra de Antonio Gramsci, entre otros. En oposición a las concepciones metafísicas, el materialismo histórico proporcionó las claves interpretativas y las categorías de análisis más recurrentes. Por un lado, la perspectiva dialéctica -más allá de las supuestas "leyes"-, contribuyó a comprender los hechos sociales como totalidades cambiantes, como síntesis de relaciones y a reconocer las contradicciones que la configuran; por otro, se incorporaron como conceptos recurrentes, los de modo de producción, fuerzas productivas, relaciones sociales de producción, clases sociales, conciencia de clase, ideología dominante, hegemonía y aparato de Estado, entre otros.

Como lo señala Luis Sime (1991) para el caso peruano, la Educación Popular no fue ajena a esta influencia al asumir y elaborar un discurso clasista de la realidad social, de lo popular y del proyecto político alternativos. Así mismo, desde este discurso fundacional, se acogió el "método dialéctico" como referente principal en las propuestas investigativas y los procesos formativos. En muchos casos, el marxismo que circuló no fue el de su creador, sino las versiones estructuralistas y esquemáticas que lo popularizaron; por ejemplo, la dialéctica se redujo a la "aplicación" mecánica de sus supuestas leyes y "principios" como que "el punto de partida y de llegada es la práctica, mediada por la teoría”.

Ya por la misma época se venía dando, al interior del propio movimiento intelectual de la izquierda mundial y latinoamericana, un cuestionamiento a las lecturas reduccionistas del marxismo y habían surgido desarrollos teóricos en torno a problemáticas referidas a la cultura, la vida cotidiana, los cambios en el modelo de acumulación capitalista y la ecología (el neomarxismo). Sin embargo, fue con el fin del régimen soviético (simbolizado 


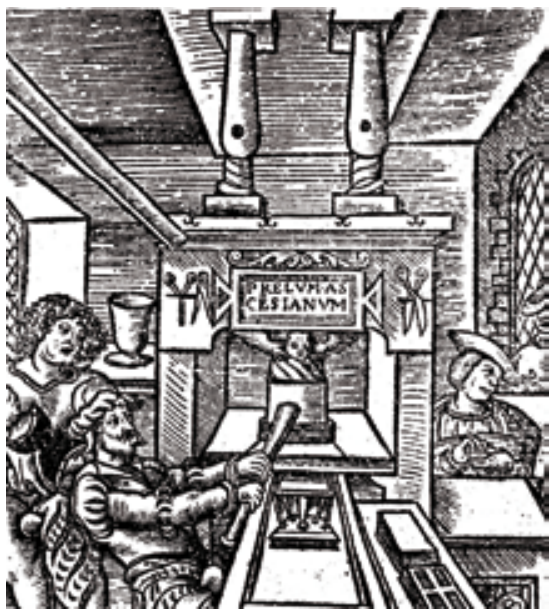

en la caída del muro de Berlín) y el descrédito de otras experiencias socialistas, que se hicieron más evidentes las limitaciones del materialismo histórico como fuente exclusiva del pensamiento crítico y del utopismo social.

Por otro lado, fueron apareciendo certeras críticas al capitalismo, al Estado y la ciencia modernas, provenientes de posiciones conceptuales no marxistas. Si bien es cierto que el llamado postmodernismo asumió la bandera de lucha contra los metarelatos teóricos y políticos clásicos como el propio marxismo, también proporcionó algunas ideas y pistas metodológicas con potencial emancipador. Por ejemplo, autores como Foucault, Deleuze, y Guattari y Derridá, aportan claves de lectura para cuestionar el poder y el capitalismo. En ese sentido, Freire y Fals Borda (1991 y 1995), han coincidido en hablar de un "postmodernismo progresista", para referirse a las convergencias entre la tradición emancipatoria latinoamericana expresada en la Educación Popular y la Investigación Acción Participativa y algunas de las ideas reivindicadas por autores contemporáneos que, sin provenir del marxismo, hacen críticas al capitalismo, como por ejemplo, las relaciones entre poder, cultura y conocimiento, el reconocimiento del potencial emancipador de los saberes subalternos y de la política menor.

En efecto, Isabel Vinent plantea que se pueden reivindicar para la educación popular las confluencias entre emancipación y posmodernismo:

En efecto, el nuevo discurso posmoderno, al ser fusionado con el pensamiento crítico, potencia las luchas emancipatorias del Sur y las luchas emancipatorias feministas... Desde las tradiciones emancipatorias de los pueblos del Sur, el postcolonialismo aporta una propuesta innovadora en la que se mezclan el feminismo, el marxismo y el postestructuralismo (Vinent, 2006, p. 34).

Desde algunas perspectivas investigativas desarrolladas por fuera y en oposición a disciplinas sociales, como el feminismo, los estudios de género, los estudios culturales, los estudios poscoloniales y los estudios subalternos, se han hecho serios cuestionamientos al universalismo y objetivismo de la ciencia social moderna y se ha puesto en evidencia su carácter patriarcal, eurocentrista, colonialista y elitista. En consecuencia, se proponen prácticas alternativas que visibilizan y cuestionan dichas relaciones de subordinación, a la vez que abren nuevas posibilidades emancipadoras.

Desde América Latina se está dando una renovación de la tradición crítica, desde la convergencia entre los aportes de autores consagrados (Fals, Quijano, González Casanova) y las reflexiones de otros pensadores latinoamericanos (Lander, Castro, Walsh, Escobar, Mignolo, Coronil); así, la tradición crítica de influencia marxista entra "en diálogo con nuevas corrientes de pensamiento, tales como la crítica al orientalismo, los estudios postcoloniales, la crítica al discurso colonial los estudios subalternos, el afrocentrismo y el posoccidentalismo" (Rodríguez, 2003, p. 10).

Tal vez el proyecto intelectual con mayor potencia crítica es la teoría o pensamiento decolonial (Mignolo, 2006) que reivindica sus raíces, no en la tradición moderna occidental, sino en las prácticas culturales de resistencia de los pueblos colonizados, y busca cuestionar y subvertir la presencia de la racionalidad y el poder colonial en diferentes prácticas de saber, de poder y de ser, que incluso se reconocen como alternativas
(Walsh, 2002). Otros autores como Josef Estermann (2006 y 2008) hablan de una filosofía andina como crítica intercultural a los proyectos hegemónicos.

Finalmente, pero no menos significativo en la construcción de paradigmas emancipadores, está el aporte de Hugo Zémelman. Este pensador chileno plantea que la apropiación crítica de la realidad histórica desde opciones de construcción de futuro, exige transgredir los límites de la racionalidad de la ciencia, dado que no dan cuenta de la complejidad de la vida social. El reconocimiento de la historicidad e indeterminación de la realidad social, así como el papel del sujeto y la subjetividad en su transformación, desborda los modos de acción científicos predominantes, limitados a lo cognitivo, a la lógica del objeto, a la explicación causal desde corpus teóricos preestablecidos y a los lenguajes cerrados (Zémelman, 2005).

Conocer la realidad desde la opción de transformación, exige una apertura gnoseológica que permita "captar" su riqueza y multiplicidad, a la vez que incorpore otras dimensiones no cognitivas del sujeto, como la voluntad. Esta racionalidad crítica, denominada por Zémelman pensar epistémico, implica posicionamiento del sujeto frente a sus circunstancias en tanto constructor de realidad, apropiación de la realidad desde diferentes ángulos y lenguajes que permita reconocer sus posibilidades de desenvolvimiento y potenciar sus sentidos. En fin, es desde la necesidad de conciencia histórica, de constitución de sujetos y de construcción de realidad que cobra sentido el conocimiento social.

\section{PISTAS PARA ELABORAR LA CARTOGRAFÍA Y LAS RUTAS DE BÚSQUEDA}

Hecho este recorrido por los motivos, concepciones y fuentes para reconstruir los paradigmas emancipadores, presento lo que podrían ser los contenidos de un programa intelectual y pedagógico encaminado a propiciar y potenciar su construcción y socialización desde la 
Educación Popular. Este "programa" implica, en primer lugar, identificar las lógicas culturales hegemónicas que pretendemos cuestionar y con las que queremos tomar distancia: "Toda forma de pensamiento crítico debe comenzar por ser una crítica al conocimiento mismo" (Santos, 2003, p. 33); en segundo lugar, delinear los principios o criterios desde los cuales renovar la tradición crítico emancipadora, y, finalmente, esbozar las implicaciones pedagógicas que para la educación popular tendría la formación en estas nuevas coordenadas culturales.

\section{EL PARADIGMA CON EL QUE SE QUIERE TOMAR DISTANCIA}

¿Cuáles son los modos de conocer, razonar o pensar y sentir hegemónicos que desde la EP criticamos y buscamos superar? En los documentos consultados, al igual que en la literatura contemporánea que reivindica los "nuevos paradigmas" hay alusiones diferentes, que van desde la civilización o cultura occidental, la racionalidad moderna, el paradigma científico clásico, el positivismo y la ideología capitalista hasta el paradigma neoliberal. Esta amplitud y disparidad confirma la insatisfacción generalizada desde diferentes prácticas culturales y políticas frente a las formas y modos predominantes de conocer y pensar que no permiten comprender el mundo ("leer la realidad") ni construir o reconocer otros mundos posibles ("transformar la realidad").

Para autores como Castoriadis, la lógica predominante en Occidente se gestó en Grecia, con Parménides, Platón y Aristóteles, filósofos que plantearon una ontológica que concibe al ser como orden: las cosas son como son y no pueden ser de otra manera; una lógica de lo mismo que deja por fuera la emergencia de lo otro y que se expresa en los principios lógicos de identidad y no contradicción que se enseñan en la escuela. Esta concepción desconfía del saber y de la creatividad de la gente común y corriente (doxa). Por eso, las verdades hay que buscarlas intelectualmente más allá del sentido común: en los fundamentos o en los fines últimos.
Esa ontología, que Castoriadis denomina identitaria, busca la verdad en el principio primero, subsumiendo lo múltiple y aniquilando la posibilidad de lo nuevo. La realidad es vista como conjuntos de objetos, donde la identidad de cada uno es su pertenencia a un conjunto predeterminado. Los "acontecimientos" particulares no son más que la realización de leyes universales o manifestación de una clase de elementos preexistentes. Por ello, esta modalidad de pensamiento es determinista: la indeterminación es desconocida o cuando reconoce lo indeterminado le asigna un lugar inferior; es un error o una anomalía pasajera que confirma el orden del universo.

Otros pensadores, como Morin (1996) y Martínez (2000), centran la crítica en la llamada ciencia clásica, hija de la modernidad europea, que se convirtió en el paradigma o "matriz epistémica dominante en los últimos cinco siglos". En esta perspectiva, los paradigmas subyacen y definen las formas de conocimiento, pensamiento y acción: "toda estructura cognoscitiva generalizada o modo de conocer, en el ámbito de una determinada comunidad o sociedad, se origina $\mathrm{o}$ es producida por una matriz epistémica" (Martínez, 2000, p. 3). Dicha matriz rige los modos de conocer y pensar, y da origen a cosmovisiones del mundo, a ideologías y a mentalidades colectivas.

La matriz epistémica moderna, se configuró desde el siglo XVI en Europa occidental y se "universalizó" (impuso) en los siglos siguientes a través de la expansión capitalista y la dominación colonial a lo largo y ancho del planeta. Sus "fundamentos", asumidos como supuestos incuestionables, han configurado los rasgos centrales de las ciencias naturales y de las ciencias sociales positivistas, y de otras esferas de la sociedad como la política y la educación, dimensiones constitutivas de la educación popular.

Edgar Morin denomina esta matriz "paradigma de simplicidad", que supone orden en el universo y persigue o excluye el desorden; que reduce el orden a una ley, a un principio; que evitando la contradicción y el azar, reduce la complejidad del mundo; que expulsa la subjetividad del conocimiento, reduciéndola a abstracción y privilegia la lógica instrumental en la investigación. En una perspectiva similar se han identificado algunos rasgos comunes de la ciencia clásica (Torres, 1996):

Determinismo: el mundo natural y social se rige por leyes universales. Al ser asumido como cosmos, como orden dado, queda por fuera lo que está dándose, lo indeterminado, lo otro. Dicha determinación es concebida como causalidad, como relaciones unidireccionales de causa-efecto: a tales condiciones, tales efectos.

Isomorfismo: estas leyes son susceptibles de descubrir mediante la razón (también universal). Es decir, esta correspondencia entre legalidad del universo y universalidad de la razón es lo que posibilita la ciencia.

Concepción lineal del tiempo: en las ciencias naturales se presuponía un espacio y un tiempo absolutos y en las ciencias histórico-sociales el imaginario de progreso (y sus correlatos: evolución social, desarrollo, etc.)

Dualismo: concibe la realidad y su abordaje desde paridades excluyentes como naturaleza/hombre, alma/cuerpo, realidad/irrealidad, práctica/teoría y sujeto/objeto.

Universalismo: así como la existencia de las leyes se da en todo tiempo y lugar, las teorías y modelos que las expresan también tienen validez universal. Dicho universalismo esconde un eurocentrismo: considerar que las afirmaciones y abstracciones hechas desde y para los países centrales, puedan "aplicarse" a las demás regiones del globo.

Racionalización: supremacía de la razón analítica, entendida como comprensión lógica de la realidad, dejando por fuera otras racionalidades. De este modo, el pensamiento narrativo y la imaginación simbólica, vitales en la mayoría de las experiencias culturales, son excluidas o subestimadas por la ciencia. 
Objetivismo: el sujeto, puede conocer "objetivamente" dichas leyes mediante la combinación de procedimientos empíricos (lexperimentación) y mentales (análisis, abstracción). Las singularidades históricas, culturales, valorativas y emocionales son "ruidos" que deben aislarse de la actividad científica.

Reduccionismo: descubrir y aplicar las leyes del mundo implica abstraerse de las contingencias de los contextos específicos, de las multiplicidades, alteridades y alteraciones. Por ello, busca reducir lo múltiple en lo único: unificar lo diverso.

Control: en la medida en que la razón descubre las leyes que rigen el mundo natural y social, éste puede ser controlado por la razón para regularlo, normalizarlo o emanciparlo.

En una perspectiva más afín a la señalada para la Educación Popular, otros autores centran su crítica al modo predominante de entender y practicar la ciencia social y sus implicaciones políticas. Es el caso de Boaventura de Sousa Santos, quien en libros como $L a$ caída del angelus novus. Ensayos para una nueva teoría social y una práctica política (Bogotá, ILSA-UN, 2003), y Renovar la teoría crítica y reiventar la emancipación social (CLACSO, Buenos Aires, 2005) hace una crítica a las ciencias sociales modernas, convertidas en una instancia hegemónica e institucionalizada.

Para este pensador comprometido con el movimiento emancipador mundial, existe en la actualidad una crisis general de las ciencias sociales constituidas en la modernidad desde unos pocos países del Hemisferio Norte, que se expresa en su imposibilidad de comprender y decir "algo nuevo" frente a las problemáticas más significativas del mundo actual. Desde el Sur, estas teorías no sólo están fuera de lugar, sino que son incapaces de comprender los problemas actuales. Desde los movimientos y organizaciones sociales alternativos, "no es simplemente un conocimiento nuevo el que necesitamos; necesitamos un nuevo modo de producción de conocimiento.
No necesitamos alternativas, necesitamos un pensamiento alternativo de las alternativas" (Santos, 2005, p.16).

Para De Sousa Santos, es necesario reinventar las ciencias sociales porque son un instrumento precioso; hoy son parte del problema, pero pueden ser parte de la solución. "Es decir, no es un problema de las ciencias sociales, sino de la racionalidad que subyace en ellas" (20). A esa racionalidad la denomina "insolente", "perezosa", dado que reduce el campo de realidad a lo dado, a lo existente. Es una "sociología de las ausencias", desde la cual lo ausente es producido sistemáticamente de cinco maneras:

1. Monocultura del saber y del rigor: reduce lo verdadero a lo científico, dejando por fuera muchas otras formas valiosas de saber ("epistemicidio").

2. Monocultura del tiempo lineal: la historia tiene un único sentido, una dirección, y los países desarrollados van adelante.

3. Monocultura de la naturalización de las diferencias que ocultan jerarquías, asimetrías y formas de dominación: minorizar e interiorizar a los "otros".

4. Monocultura de la escala dominante: el universalismo y los estadosnación.

\section{Monocultura del productivismo ca-} pitalista.

Esta racionalidad monocultural genera cinco formas de ausencia: el ignorante, el residual, el inferior, el local o particular y el improductivo, sobre las cuales justifica su dominación por parte de la ciencia, la economía capitalista, el Estado y las vanguardias culturales y políticas. Finalmente, otros intelectuales contemporáneos enfilan sus críticas a la cultura que se ha venido imponiendo de la mano de la implantación del modelo neoliberal a partir de la penúltima década del siglo pasado. Se trata de un pensamiento único y una ética legitimadores del capitalismo y del orden político imperante.
En la medida en que se configura como un sistema rígido de creencias y verdades incuestionables, algunos Ilegan a hablar del neoliberalismo como una nueva religión. Por un lado, exalta como valores deseables para todas las esferas de la vida personal y social, la racionalidad capitalista: idolatría del dinero, mercantilización de todas las esferas de la vida social, sed insaciable de ganancia y lógica del costo beneficio, competencia sin límites, y consumismo. Por otro lado, exalta valores funcionales al modelo económico: egoísmo extremo, indiferencia frente a las injusticias, conformismo, sumisión, conservadurismo moral, deificación de lo individual y lo privado, satanización de lo colectivo y de lo público, abnegación, fatalismo, desesperanza, escepticismo frente toda forma de compromiso y renuncia a cualquier voluntad de cambio. La generalización de estos valores consolida la economía capitalista, garantiza el control sobre la población, debilita el tejido social, subordina diferentes prácticas sociales a la lógica empresarial, desalienta cualquier deseo o vocación de transformación social y naturaliza el orden social.

Lo planteado no significa que la racionalidad que orienta totalmente los discursos y prácticas educativas populares sea la cultura occidental, la ciencia moderna y la sociología de las ausencias, pero es innegable que esta corriente pedagógica no es ajena a las mismas, y varios de sus rasgos la constituyen y permean. Lo que habría que hacer es identificar cuándo estas racionalidades están presentes en nuestras lecturas de realidad, en nuestros discursos, en nuestras prácticas y nuestras decisiones, bloqueando o impidiendo pensamientos y procesos emancipadores. Así mismo, consecuentemente con lo que planteamos en el numeral siguiente, también desde la educación popular, al igual que otras corrientes culturales alternativas, se han gestado -intencionalmente o no - modos de conocer, pensar y actuar que la subvierten y que son portadores de otras racionalidades y subjetividades emergentes. Como se dijo, es urgente reconocerlas, reflexionarlas y potenciarlas. 


\section{PISTAS PARA CONOCER, PENSAR E IMAGINAR(NOS) DE OTRO MODO}

Queda lo más difícil: reconocer y construir las nuevas claves de pensamiento, los nuevos modos de conocimiento y los nuevos sistemas de valores y creencias desde las cuales comprender críticamente el mundo y orientar sus transformaciones. Siguiendo el orden de los autores que develan las limitaciones de los paradigmas occidental, moderno, científico social y cultura neoliberal predominantes, se presentarán las alternativas epistémicas, culturales y éticas propuestas.

Según Castoriadis, hay que pensar el ser, la realidad, como autocreación, como potencia indeterminada y al propio tiempo determinante. La historia humana no está determinada, es autocreación, de ahí la necesidad de reconsiderar una ontología desde la imaginación radical. Para el autor, la sociedad no es un conjunto ni un conjunto de conjuntos (sistema): es magma y magma de magmas. Para este pensador, el mundo es esencialmente caos, abismo, sin fondo. El cosmos -orden- surge del caos, es decir, de la nada, del vacío. El mundo no está totalmente organizado y descansa sobre un desorden primordial: las formas que conforman el mundo como cosmos surgen de lo informe y de lo indeterminado. Así, lo real no es enteramente racional; es una mezcla de desorden y orden, determinación e indeterminación, de lo definido y de lo indefinido.

Por otro lado, reconocida la insuficiencia de esta matriz epistémica para comprender lo real y generar sentidos plausibles, Edgar Morin propone una reforma del pensamiento desde la perspectiva o paradigma de la complejidad. En primer lugar, éste debe complementar el pensamiento que aísla (analítico) con el que une: que vincule y a la vez distinga, sin separar; y en segundo lugar, debe reconocer los entramados de las interacciones entre los fenómenos, sus tensiones, su aleatoriedad (Cfr. Morin, 1996, p. 33). Pensamiento complejo que reconozca que el universo no es sólo orden dado sino también desorden y autoorganización. Por ello, el pensamiento complejo admite confluencias y certezas, pero también diferencias e incertidumbre (Morin, 1996).

De Sousa Santos plantea que si se quiere generar una alternativa al orden mundial preponderante, hay que generar desde los movimientos altermundistas un pensamiento y unas ciencias sociales críticas capaces de subvertirlo, de generar otros mundos posibles. Para ello propone una sociología de las emergencias. Para controvertir la sociología de las ausencias, hay que hacer presente lo que está ausente; esto se logra superando las cinco monoculturas por cinco ecologías: 1) Ecología de los saberes, que posibilite un diálogo entre las ciencias y otras prácticas culturales como el saber ancestral, el saber campesino y popular; 2) Ecología de las temporalidades; 3) Ecología del reconocimiento; 4) Ecología de la "trans-escala"; y, 5) Ecología de las productividades.

Las ecologías van a permitir dilatar el presente con muchas más experiencias relevantes para todos. Para contraer el futuro, se requiere de una sociología de las emergencias: reconocer las señales, las pistas, las latencias que son posibilidades de futuro desacreditadas por la racionalidad dominante. La sociología de las emergencias produce experiencias que no están dadas, pero que son posibles y ya existen como emergencias. La sociología de las ausencias y la sociología de las emergencias van a producir una nueva realidad, otros mundos posibles.

Para generar sentido a partir de lo planteado, hoy no son admisibles una epistemología y una teoría generales. No hay teoría que pueda dar cuenta de toda la realidad. No puedo reducir la heterogeneidad del mundo a la homogeneidad de una teoría. Todo esto debe generar una nueva manera de entender, de articular conocimientos, prácticas, sujetos. Hoy hay muchos lenguajes para nombrar la dignidad humana y para nombrar un futuro mejor. No hay cultura humana que sea completa, por ello se requiere interculturalidad e intersocialidad. Debemos asumir diferentes retos:
6. Reivindicar las posibilidades emancipatorias que estaban en este conocimiento emancipador: una utopía crítica.

7. Distinguir objetividad de neutralidad.

8. Desarrollar subjetividades rebeldes. Pasa por fortalecer voluntades, creencias, emociones, entre otros.

9. Crear una Epistemología desde el Sur: superar la colonialidad del poder y del saber. Las estructuras del poder se ven mejor desde los márgenes.

Por último, si reconocemos que la globalización neoliberal ha significado la imposición de una ética funcional a su proyecto, también debemos dar cuenta de las propuestas de una "ética de la liberación" frente a la globalización excluyente. En términos de Dussel (2005), guiada por el proyecto neoliberal, la humanidad va hacia el abismo; para salvarnos de este suicidio colectivo debemos construir una nueva ética universal centrada en la defensa y producción de la vida de y para todos. Frente a la "teología neoliberal" y desde la Teología de la Liberación y su opción por los humildes, se propone una ética de la justicia, de la gratuidad, de la compasión, de la alteridad, de la solidaridad, de lo comunitario incluyente, de la vida, de la hospitalidad, de la contradicción, de la denuncia y de la utopía.

\section{LAS EXIGENCIAS PEDAGÓGICAS}

Para la EP no basta el reconocimiento ni la contribución a la construcción de un pensamiento crítico y una racionalidad epistémica alternativa a la que ha predominado desde la cultura occidental, la ciencia moderna y el llamado pensamiento único hegemónico; es necesario generar propuestas de formación que posibiliten el reconocimiento, la apropiación y la construcción de racionalidades y subjetividades emancipadoras, por parte de los educadores populares $-y$ consecuentemente, de los sujetos de sus prácticas educativas - 
Es decir, es necesario pensar en una formación surgida a partir de estos "paradigmas emancipadores". Asumir este desafío implica reconocer que formarse en estas racionalidades y subjetividades alternativas no debe limitarse a obtener y divulgar información o contenidos críticos, como, por ejemplo, análisis de datos y de coyuntura realizados por expertos. Más bien, se trata de potenciar las estrategias de conocimiento crítico y de pensamiento emancipador de los sujetos, a partir de reconocer sus saberes y disposiciones previas, así como de asumir las opciones, los criterios y los aportes pedagógicos provenientes de la propia educación popular y de las otras prácticas culturales y sociales críticas señaladas.

De nuevo Paulo Freire nos ofrece las líneas centrales de lo que pueden ser los rasgos (las "virtudes" diría él) de una posición y una conciencia críticas del mundo. A continuación, retomaré algunos de los planteamientos expuestos en su libro póstumo Pedagogía de la indignación; asumiendo su propia invitación, "pondré en diálogo" sus ideas con las de otros pensadores críticos. A continuación esbozo algunos principios y criterios para la construcción de una propuesta de formación de educadores populares en perspectiva de los paradigmas emancipatorios:

\section{Curiosidad epistémica}

En primer lugar, debe existir capacidad de asombro, disposición, voluntad de querer pensar desde una perspectiva crítica; no solo porque nadie enseña a pensar a otro, sino porque, desde la educación popular, asumir paradigmas emancipatorios se asume como una opción coherente con su sentido y razón de ser.

Ya Freire ha señalado que no es posible conocer si no hay deseo de conocer, si no hay involucramiento con lo que se aprende. Conocer no es una actividad aséptica: es una actividad intencional y ligada de manera densa a un proyecto

Los seres humanos, hombres y mujeres, somos pro-yectos. No estamos yectos, no estamos muertos. Conocer es una actividad viva. Lo contrario no es conocer, es sólo tragar momias conceptuales y luego escupirlas ante alguien que solicita esa tarea para avalar que el conocimiento existe en quien repite lo que le enseñaron (no lo que aprendió). El/la que conoce no se adapta al mundo, sino que crea el mundo" (Freire, 2001, p. 50).

\section{Colocarse críticamente frente al mundo}

La curiosidad es necesaria, pero no suficiente en la perspectiva de asumir un pensamiento y una subjetividad críticos. Ella plantea "colocarse frente a la realidad" (Zémelman), posicionarse críticamente frente al contexto, a las circunstancias históricas que nos desafían y nos condicionan. Pensar críticamente no es una facultad o proceso abstracto sino concreto, histórico, que exige del sujeto reconocerse y asumirse frente a dicha historicidad, es decir, preguntarse para qué y para quienes va a servir el conocimiento o pensamiento que quiero generar. Así, cualquier esfuerzo investigativo, intelectual o educativo, debe partir de una actitud intelectual y moral crítica frente al contexto. Dicha actitud implica sensibilidad al contexto y capacidad para reconocer lo que Freire denominó "situaciones límite", acontecimientos y realidades emergentes, a partir de las cuales reconocer los factores, elementos e ideas que permiten comprenderlas.

\section{Pensar desde opciones de transformación}

La aprehensión crítica del mundo, más que operación cognitiva es un desafío frente a la necesidad de transformarlo, que requiere lucidez y rigor, pero también voluntad de hacerlo: "Si en realidad no estoy en el mundo para adaptarme a él sino para transformarlo, no es posible cambiarlo sin un cierto sueño o proyecto de mundo..." (Freire, 2001, p. 43).

Este posicionamiento ético y político de construcción, implica reconocer los condicionamientos y límites que impone la realidad, pero también la posibilidad y capacidad para hacerlo -con otrosdesde sueños, utopías compartidas. Es decir, es fundamental reconocernos como sujetos de poder, saber y voluntad para no caer ni en el determinismo fatalista, ni en el voluntarismo ingenuo, como insiste Freire. El reivindicar hoy la necesidad y la plausibilidad de pensar y construir "otros mundos posibles" cuestiona la ideología neoliberal que plantea la imposibilidad e indeseabilidad del cambio. Freire también insiste en la necesidad de esperanza y en la confianza en la construcción de utopía; sin visiones de futuro, no hay esperanza: "El ejercicio constante de una lectura de mundo, que exige la comprensión crítica de la realidad, supone, por una parte, su denuncia, y por otra, el anuncio de lo que aún no existe" (p. 52).

\section{Pensar críticamente implica reconocer las formas de razonar, conocer y valorar que lo impiden}

Es necesario reconocer que cargamos con una herencia cultural impregnada de racionalidades, formas de conocer, de valorar y de sentir acríticas, ingenuas, fatalistas, dogmáticas, dicotómicas, excluyentes, que bloquean el pensamiento y la voluntad de transformación. Como la afirma Lipman, retomando a Paul,

[...] el pensamiento crítico se presenta como un desafío permanente contra el dogmatismo, la estrechez de miras y la manipulación intelectual, hacia una sociedad crítica que se enfrente al adoctrinamiento y cultive la interrogación reflexiva, la independencia intelectual y el disenso razonado (Lipman, 1998, p. 105).

\section{Pensamiento e imaginación críticos, más que contenidos críticos}

Pensar críticamente no es hacer afirmaciones o manejar información con contenido crítico, sino adquirir una manera de razonar capaz de leer críticamente el mundo por sí mismos. Para Lipman, el Pensamiento Critico implica la formación de criterios para comprender y resolver problemas concretos en contextos cambiantes. Los criterios son 
razones valiosas que justifican y defienden formas de pensar y hacer que consideramos relevantes, confiables y potentes. Se generan y son pertinentes en comunidades interpretativas específicas y se expresan a través de principios, acuerdos, valores, normas, propósitos y pautas de acción comunes; involucran esquemas cognitivos (análisis, argumentación, interpretación y evaluación) y valores compartidos (sensibilidad al contexto, humildad, apertura cognoscitiva, solidaridad y compromiso) desde los cuales se aprehende la realidad y se orientan acciones individuales y colectivas (toma de decisiones, diálogo y solución de problemas).

Desde una perspectiva de educación popular, pensar críticamente implica superar todo pensamiento reduccionista, simplificador y dicotómico, que permita reconocer la complejidad y pluralidad de la vida social, que posibilite miradas de conjunto y admita lo determinado y lo indeterminado, las certezas y las incertidumbres, lo sabido y lo inédito, lo general y lo singular, lo común y la diferencia, entre otros.

\section{Pensar críticamente no se agota en lo cognitivo}

Freire ha sido insistente en mostrar que el asumir una posición crítica no es un asunto meramente intelectual: involucra a los sujetos en todo su ser; por eso, es más pertinente hablar de subjetividades críticas para involucrar tanto las opciones y concepciones concientemente asumidas, como los valores, las voluntades y actitudes críticas necesarias para posicionarse y transformar la realidad.

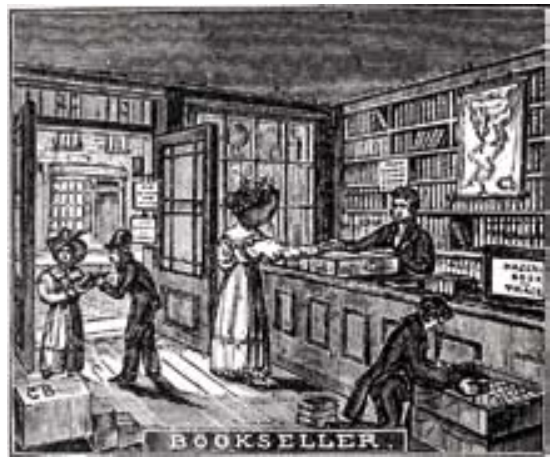

Frente a la cultura hegemónica neoliberal, con sus valores subordinados a la lógica del mercado, es necesario reivindicar unos valores coherentes con el proyecto transformador, como la humildad, el compromiso y la solidaridad, tal como lo plantea Alfredo Ghiso en un texto reciente, en el que se pregunta: ¿Cómo discutir sobre la solidaridad en un mundo marcado por la exclusión, el hambre, la intolerancia y la guerra que sólo parece reconocer las leyes del más fuerte? La convivencia, la cohesión social, la solidaridad no existen en el aire; sus formas y contenidos son concretos, prácticos y útiles, tal como lo señala Paulo Freire, al ver la solidaridad

no como algo con lo cual uno nace, es decir, no como un regalo que uno recibe, sino como una forma de ser, de encarar, de comprometerse, de comprender; que se crea a través de la práctica....No es una cualidad abstracta que existe antes de nosotros, sino que se crea con nosotros (Ghiso, 2005, p. 5).

El autor, al plantear la solidaridad como itinerario pedagógico señala dos asuntos: uno, que los valores como referentes de vida no pueden ser tratados en paralelo o en forma fragmentada; todo lo contrario, toca tener una lectura y una estrategia que nos permita proponer integralidad. El otro es resaltar la necesidad de hacer explícita la vivencia cotidiana de los valores y esto tiene que objetivarse en las dinámicas y proyectos educativos institucionales.

\section{La formación de pensamiento y subjetividad crítica es una experiencia colectiva}

Freire propuso que la educación debe servir para que hombres y mujeres se formen como sujetos autónomos y críticos, a partir del diálogo y de la acción transformadora de su realidad. En una entrevista con Rosa María Torres en 1985, ella señaló que "el educador tiene que ser una especie de vagabundo permanentemente: caminar para allá y para acá constantemente, para ir al aquí de los educandos e intentar ir con ellos, no a su acá, sino a su allá que está en el futuro".
Del mismo modo, la construcción de un pensamiento y unas subjetividades alternativos solo es posible a partir del diálogo entre quienes, desde sus singularidades y diferencias, compartimos la voluntad e interés de transformar la realidad en función de visiones de futuro emancipadoras. En ese sentido, el pensamiento crítico se construye y regula intersubjetivamente en comunidades dialógicas de indagación:

El conocimiento no es algo dado y cerrado, sino que se reconstruye permanentemente de forma intersubjetiva. La interrogación, el asombro, el cuestionamiento, el misterio, el diálogo, son motores de indagación intelectual, social, artística, moral y política (Ferrer, 1998, p. 23).

\section{Reflexividad}

Pensar críticamente, exige estar alerta para no naturalizar nuestra propia mirada y convertir en objeto de reflexión crítico todas y cada una de las operaciones mentales, así como las decisiones que tomamos. Corresponde a lo que Freire llama una actitud autocrítica frente a nuestras propias lecturas y prácticas frente a la realidad. Para Lipman,

[...] el pensamiento complejo es el que es conciente de sus propios supuestos e implicaciones, así como de las razones y evidencias en las que apoya sus conclusiones... Examina su metodología, sus procedimientos, su perspectiva y su punto de vista propios... de la misma manera que implica pensar sobre la materia objeto de examen (Lipman, 1998, p. 67).

\section{El ser crítico busca una coherencia entre el pensar y actuar}

El pensamiento y la subjetividad crítica cobra sentido en la medida en que posibilita orientar adecuadamente las prácticas transformadoras (praxis). Esta articulación de teoría y práctica acorde con los criterios y valores alternativos, corresponde a lo que los griegos denominaban phronesis: el actuar desde el buen juicio, con prudencia y responsabilidad. El pensamiento crítico posibilita 
una autonomía solidaria de lo sujetos. En fin, podemos afirmar que la educación desde paradigmas críticos debe fomentar comunidades de indagación y acción, con capacidad de asombro y curiosidad epistémicos, sensibles hacia las problemáticas del contexto, con opciones de futuro viables, autónomas, reflexivas, dialógicas y responsables.

\section{FORMACIÓN EN PARADIGMAS EMANCIPADORES, DESAFÍO DE LA EDUCACIÓN POPULAR}

Estas virtudes propias del pensamiento y la acción críticos, no se adquieren de la noche a la mañana. Son un proceso de construcción paulatino, colectivo, práctico y reflexivo. Cada comunidad de educadores debe ir estableciendo sus estrategias y dispositivos para que sus integrantes vayan adquiriendo pensamiento crítico. Por ejemplo la participación en reuniones, la entrega de responsabilidades, el estudio de materiales, la participación en cursos y talleres y las sesiones de crítica y autocrítica. En una escala mayor, los colectivos nacionales y las redes de educadores a nivel regional, en la medida en que generan una dinámica de discusión acerca de sus contextos y sentidos que movilizan, así como a la construcción colectiva de proyectos, posibilitan la formación de pensamiento crítico.

\section{BIBLIOGRAFÍA}

Alvarez, E y Dagnino. (2001). Cultura política y políticas culturales en los movimientos sociales latinoamericanos. Bogotá: ICANH - Taurus.

Berger, P y Luckmann, T. (1997). Modernidad, pluralismo y crisis de sentido. Barcelona: Paidos.

De Souza, J. F. (2001). Atualidade de Pulo Freire. NUPEP - CIIE, Recife.

Dusell, E. (2006). Ética de la liberación. Bogotá: Nueva América.

Esterman, J. (2006). La filosofía andina: sabiduría indígena para un mundo nuevo. La Paz: ISEAT.
Así mismo retomo a Isabel Vinient (2004), cuando afirma que la epistemología de la Educación Popular se concibe como un proceso en el cual la investigación y la educación están permanentemente relacionadas. Tenemos la responsabilidad de dar continuidad y "hacer crecer" los sistemas de ideas que nos han legado personajes como Paulo Freire y Orlando Fals Borda. También que la corriente pedagógica crítica debe nutrirse de corrientes alternativas concluyentes como el feminismo y los estudios postcoloniales, las cuales aportan perspectivas y claves de interpretación y acción que potencian su sentido emancipatorio.

Por ello, considero que los retos que se le plantean a la EP con respecto a su contribución a la construcción de paradigmas emancipadores se sitúan especialmente en tres campos: la formación, la investigación y la promoción de la reflexión, discusión y producción en torno a las grandes apuestas éticas políticas y perspectivas que nos dan identidad como educadores populares.

1.Retomar la política de formación. Es urgente elaborar y desarrollar una propuesta de formación de Educadores Populares que contribuya al reconocimiento y potenciación de los saberes y pensamientos emancipadores presentes en las prácticas de las organizaciones

Esterman, J. (2008). Si el sur fuera el norte. Chakanas e interculturalidad entre Andes y Occidente. Quito, Abya Yala.

Fals Borda, O. (1991), Acción y conocimiento. Bogotá: CINEP.

FALs Borda, O. (1995). Investigación Acción, ciencia y educación popular en los 90'. La Habana: Consejo de Educación de Adultos de América Latina (CEAAL), Taller Internacional.

FERRE, v. (1998). Introducción. En: LIPMAN, M. Pensamiento complejo y educación. Madrid: La Torre. que hacen EP, a la vez que posibilite el diálogo con los aportes provenientes de otras corrientes intelectuales, culturales y educativas críticas. Puede combinar la modalidad virtual, apoyada en la plataforma del CEAAL con encuentros nacionales y por campos temáticos de trabajo, que permiten una mayor intensidad en la interacción.

2.Fortalecer la sistematización de experiencias, no sólo para socializar la producción de conocimientos, las reflexiones y los intercambios metodológicos al respecto, sino también para promover la realización de proyectos específicos de sistematización del trabajo en redes y en torno a experiencias significativas en los ejes de acción del CEAAL.

3.La Piragua así como otras publicaciones de EP deben continuar estimulando la reflexión y discusión de la producción de pensamiento y de conocimiento sobre y desde la Educación Popular como contribución a la formación en general y al diálogo con otros educadores populares y otros actores sociales, educativos y políticos que comparten nuestro horizonte utópico. Así mismo, lo desarrollos de las reflexiones y debates pueden divulgarse por otros medios impresos y virtuales editados por instituciones académicas y educativas.

FREIRE, P. (1985). Reflexión crítica sobre las virtudes del educador. Buenos Aires: Mimeo.

Freire, P. (2001). Pedagogía de la indignación. Madrid: Morata.

Fried, D. (1994). Nuevos paradigmas: Cultura y subjetividad. Buenos Aires: Paidos.

GHIso, A. (2005). Apunte freiriano. Solidaridad como itinerario del quehacer pedagógico Medelín. [Inédito]

LipMAn, M. (1998). Pensamiento complejo y educación. Madrid: La Torre. 
Mıgnolo, W. El pensamiento decolonial: desprendimiento y apertura. Un manifiesto. Mimeo. s. d.

Morin, E. (1992). El método. Las ideas. Madrid: Cátedra.

Morin, E. (1996). Introducción al pensamiento complejo. Buenos Aires: Gedisa.

Osorio, M. (1996). Murió la pedagogía, viva la pedagogía. En Aportes, 41. pp 29-38

Pagano, A. (2000). Los desafíos de la educación popular en el siglo XXI. En La Piragua, 18.

Pérez, E. (2000). El reto fundamental. En La Piragua, 18. pp. 43-44

Picón, C. (2005). Desafíos de la educación popular. En La educación popular hoy: avances y desafíos. Lima: Colectivo CEAAL.

PolRIer, N. (2006). Castoriadis. El imaginario radical. Buenos Aires: Nueva Visión.

Santos Boaventura de Sousa (2003). La caída del angelus novas. Ensayos para una nueva teoría social y una nueva práctica política. Bogotá: ILSA - Universidad Nacional de Colombia.

Santos Boaventura de Sousa (2006). Renovar la teoría crítica y reinventar la emancipación social. Buenos Aires: Consejo Latinoamericano de Ciencias Sociales (CLACSO).

SIME, L. (1991). Los discursos de la educación popular. Lima: Tarea.

TAMAYO, J. (s. f.). Ética liberadora del cristianismo frente a la teología neoliberal del mercado. Madrid: La lira

ToRres, A. (1996). Enfoques cualitativos y participativos de investigación social. Bogotá: UNISUR.

ToRres, A. (2007). Subjetividad y sujeto. Perspectivas para la investigación social y educativa. Revista Colombiana de Educación, 50. pp. 87-104

Torres, A. (2008). La educación popular. Trayectoria y actualidad. Bogotá, El Búho.

Valencia, G; De la garza, E y Zemelman, $\mathrm{H}$. Coordinadores (2002). Epistemología y sujetos. México D.F.: Universidad Autónoma de México (UNAM) - Plaza y Valdés.

Wallerstein. (1996). Abrir las ciencias sociales. México: Siglo XXI Editores.

(1998). Impensar las ciencias sociales. México: Siglo XXI Editores.

WALSH, C. et al. (2002). Indisciplinar las ciencias sociales. Quito: Universidad Andina Simón Bolívar (UASB) y Ediciones Abya - Yala.

Zémelman, H. (2005). Voluntad de conocer. El sujeto y su pensamiento en el pensamiento crítico. Barcelona, Anthropos y Centro de Investigaciones humanísticas de la Universidad Autónoma de Chiapas.

ZıвECHI. (2003). Movimientos sociales en América Latina: tendencias y desafíos. En Revista OSAL, 8, pp. 185-188

\section{DOCUMENTOS}

Consejo de Educación de Adultos de AméRICA LATINA (CEAAL), (2006). Incidencia en políticas educativas. Reflexiones $y$ retos. Bogotá-Colombia.

Consejo de Educación de Adultos de AméRICA LATINA (CEAAL), (2005). Encuentro Taller CEAAL Región Andina 2005. Lima-Perú.

Consejo de Educación de Adultos de AméRICA LATINA (CEAAL), (2005). Foro público: La educación popular hoy: avances $y$ desafíos. Lima- Perú.

Leis Rául (2007). Desafíos de la educación popular y del CEAAL. Diapositivas.
Instituto de Promoción y Ayuda al DeSARROLLO (IPADE), (2004). Memorias del foro La educación popular ante la educación formal y los nuevos desafíos. Managua-Nicaragua.

IPADE-CeaAl (2005). Memorias del Encuentro Nacional de Experiencias de Alfabetización. Managua-Nicaragua.

Colectivo CEAAL-Panamá y Comisión de JustiCIA Y PAZ (2004). Memorias del Encuentro de educadores populares por el desarrollo sostenible, la democracia y los derechos humanos. Panamá, 22 y 23 de enero de 2004.

NúÑEZ C. Reflexión a partir de la lectura de Paulo Freire como lectura actual de educación popular, s. d.

Puntual P y Pereira Silva M.J. Balance general de la consulta sobre Educación Popular y Acción del CEAAL, s. d.

VINIENT I. (2004). Nuevos paradigmas, escenarios y desafíos de la educación popular hoy. Una interpretación feminista. Panamá, CEAAL.

ReVISTAS del CEAAL (Secretaría general, Panamá):

La Piragua (2005). Incidencia en Políticas Públicas, núm. 22.

La Piragua (2006). Sistematización de experiencias, núm. 23.

La Piragua (2006) América Latina nos reta, núm. 24.

La Piragua (2007). América Latina sin analfabetismo, núm. 25.

La Piragua (2007). Incidencia en Políticas Públicas: poder construyendo, núm. 26

La Piragua (2008). Educación Popular y movimientos sociales hoy: nuevos retos y compromisos, núm. 27.

Alternativas. Revista de Educación Popular. (2006). Managua, núm.1.

Alternativas. Revista de Educación Popular. (2007. Managua, núm. 2. 